\title{
2754A: a new inhibitor of VEGFR-2 isolated from the Streptomyces sp. 2754
}

\author{
Zhong-ke Jiang, Lian-hong Guo, Yang Zhang, Cheng-hang Sun, Yuan Li, Jian-bo Wu and Rong Jiang
}

The Journal of Antibiotics (2010) 63, 721-723; doi:10.1038/ja.2010.117; published online 20 October 2010

Keywords: 2754A; antagonist; Streptomyces sp. 2754; VEGF; VEGFR-2

Angiogenesis has an important role in solid tumor growth and tumor metastasis. VEGF functions as a highly specific mitogen directly involving in the process of angiogenesis, which induces endothelial cell division and proliferation and also increases vascular permeability. ${ }^{1,2}$ VEGF performs its function through binding to special receptors. Studies have showed that VEGFR-2 is the major signal transducer for the differentiation and proliferation of endothelial cells. Consequently, inhibition of VEGFR-2 signal is an effective way to block tumor angiogenesis. ${ }^{3,4}$ In the course of screening for VEGFR-2 inhibitor, a new compound, 2754A (1, Figure 1) was isolated from the Streptomyces sp. 2754. In this paper, we report the fermentation, isolation, physico-chemical properties, structure elucidation and bioactivities of 2754A.

A stock culture of the strain Streptomyces sp. 2754 was maintained on yeast and malt extract with glucose International Streptomyces Projects Medium 2 agar slant consisting of $0.4 \%$ yeast extract (Beijing Aoboxing Biotechnology, Beijing, China), 1.0\% malt extract (Beijing Aoboxing Biotechnology), $0.4 \%$ glucose and $1.2 \%$ agar ( $\mathrm{pH} 7.1$ ). The stock culture was inoculated into $250-\mathrm{ml}$ Erlenmeyer flasks containing $50 \mathrm{ml}$ of medium consisting of $0.5 \%$ yeast extract (Beijing Aoboxing Biotechnology), $0.5 \%$ glucose, $0.5 \%$ tryptone, $0.5 \%$ beef extract, $0.4 \%$ corn steep liquor (North China Pharmaceutical Corporation, Hebei, China), 1.0\% soybean extract (Beijing Comwin Pharm-Culture, Haidian, Beijing, China), $2.0 \%$ starch and $0.4 \% \mathrm{CaCO}_{3}$ (pH 7.1). The flask culture was incubated on a rotary shaker $(250$ r.p.m. $)$ at $28^{\circ} \mathrm{C}$ for $48 \mathrm{~h}$. The seed culture $(5 \mathrm{ml})$ was transferred into each of the $100,500-\mathrm{ml}$ Erlenmeyer flasks containing $100 \mathrm{ml}$ of the same medium. The fermentation was carried out at $28^{\circ} \mathrm{C}$ for $96 \mathrm{~h}$ on a rotary shaker ( 250 r.p.m.).

The fermentation broth (101) was filtered and the filtrate was absorbed on a column of Amberlite XAD-5 (Amberlite XAD-5 Macroporous Resin, Sigma, St Louis, MO, USA) (11), after washing with 41 of water, 31 of $30 \%$ aqueous acetone and 31 of $50 \%$ aqueous acetone, successively, the absorbed materials were eluted with 31 of $80 \%$ aqueous acetone. The fraction eluted with $80 \%$ aqueous acetone showed the VEGFR-2 antagonistic activity. The active fraction was concentrated in vacuo and lyophilized to obtain a crude powder $(2.8 \mathrm{~g})$. It was then chromatographed on a column of Sephadex LH-20 (Pharmacia, Sweden, $1.5 \times 100 \mathrm{~cm}$ ), developed with methanol. The first yellow fraction showing the activity was concentrated to give a yellow material $(12 \mathrm{mg})$. This material containing enriched 1 was finally purified by medium-pressure liquid chromatography (Yamazen FMI-C pump, Yamazen, Japan; column: Ultra-pack ODS, 15× $300 \mathrm{~mm}$, 30 per $50 \mu \mathrm{m}$; mobile phase: $30 \%$ aqueous acetonitrile; flow rate: $1 \mathrm{ml} \mathrm{min}^{-1}$ ) to yield $\mathbf{1}(1.5 \mathrm{mg})$ and $\mathbf{1}$ of $14 \mathrm{mg}$ was obtained from 1001 of the fermentation broth.

Compound 1 was obtained as pale yellow amorphous powder and is soluble in methanol, acetonitrile and dimethyl sulfoxide, but insoluble in $n$-hexane and water. The other physico-chemical properties of $\mathbf{1}$ are as follows: HR-ESI-MS $(\mathrm{M}+\mathrm{Na})^{+}(\mathrm{m} / \mathrm{z}) 373.0829$, calcd. 373.0899 for $\mathrm{C}_{17} \mathrm{H}_{18} \mathrm{O}_{8}$; $\lambda \lambda_{\max }^{\mathrm{MeOH}} \mathrm{hm}(\log \varepsilon) 202$ (4.13), 231 (4.35) and 345 (3.73); IR $v_{\max }(\mathrm{KBr}) \mathrm{cm}^{-1} 3422,2951,1709,1656,1605,1578$, 1266, 1037 and 758. The direct connectivity between protons and carbons was established by the heteronuclear single quantum coherence. The ${ }^{1} \mathrm{H}$ - (nuclear magnetic resonance) $\mathrm{NMR}$ and ${ }^{13} \mathrm{C}-\mathrm{NMR}$ spectral data of 1 are shown in Table 1.

Three carbonyl carbon signals $(\delta 198.97,193.19$ and 171.49$)$ and six aromatic carbon signals $(\delta 162.21,137.00,132.84,124.17,119.33$ and 115.78 ) were readily observed by analysis of ${ }^{13} \mathrm{C}-\mathrm{NMR}$ and DEPT of $\mathbf{1}$. Further analysis of the six aromatic carbon signals through heteronuclear signal quantum coherence together with ${ }^{1} \mathrm{H}-{ }^{1} \mathrm{H}$ COSY and HMBC (Figure 2) revealed that three quaternary carbon signals at $\delta$ $132.84(\mathrm{C}-5 \mathrm{a}), \delta 115.78$ (C-9a) and $\delta 162.21(\mathrm{C}-9)$, and three tertiary carbon signals at $\delta 119.33$ (C-6), $\delta 137.00(\mathrm{C}-7)$ and $\delta 124.17$ (C-8) formed a 1, 2 and 3 -trisubstituted benzene ring, as proton signal at $\delta$ $7.64(1 \mathrm{H}, \mathrm{t}, \mathrm{J}=7.8 \mathrm{~Hz}, 7-\mathrm{H})$ was coupled with proton signals at $\delta 7.57$ $(1 \mathrm{H}, \mathrm{d}, \mathrm{J}=7.8 \mathrm{~Hz}, 6-\mathrm{H})$ and $\delta 7.27(1 \mathrm{H}, \mathrm{d}, \mathrm{J}=7.8 \mathrm{~Hz}, 8-\mathrm{H})$ in ${ }^{1} \mathrm{H}-{ }^{1} \mathrm{H}$ COSY. Both $8-\mathrm{H}$ and $6-\mathrm{H}$ were long-range correlated with $\mathrm{C}-9 \mathrm{a}$, and 7-H was long-range correlated with C-9 and C-5a in HMBC. 
By tracing cross peaks from the aromatic proton $(6-\mathrm{H})$ in $\mathrm{HMBC}$, the carbonyl carbon of $\delta 193.19$ (C-5) was assigned. The proton signals at $\delta 11.61$ was also readily observed and assigned to a phenolic hydroxyl proton (9-OH), according to the chemical shift of 162.21 (C-9), a phenolic hydroxyl was substituted at C-9, and according to the chemical shift of $11.61(9-\mathrm{OH})$, it should form an intramolecular hydrogen bond with a carbonyl group, ${ }^{5,6}$ so another carbonyl carbon

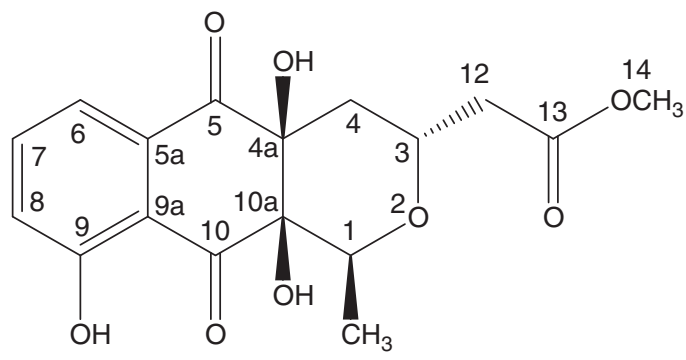

Figure 1 Structure of 2754A (1).

Table 1 NMR data of 2754A (1) in $\mathrm{CDCl}_{3}$

\begin{tabular}{|c|c|c|c|c|}
\hline Position & $\delta_{C^{\mathrm{a}}}$ & $\delta_{H}(m u l t, J(\text { in } H z))^{b}$ & ${ }^{1} \mathrm{H}_{-}{ }^{1} \mathrm{H} \cos Y$ & $H M B C$ \\
\hline 1 & 74.47 & $4.32(1 \mathrm{H}, \mathrm{q}, \mathrm{J}=7.2)$ & 11 & $3,4 a, 11$ \\
\hline 3 & 62.38 & $4.59(1 \mathrm{H}, \mathrm{m})$ & 4,12 & \\
\hline 4 & 32.93 & $\begin{array}{l}1.95(1 \mathrm{H}, \mathrm{dd}, \mathrm{J}=2.4,12.6) \\
2.28(1 \mathrm{H}, \mathrm{dd}, \mathrm{J}=15.0,12.6)\end{array}$ & 3 & $\begin{array}{c}4 a, 10 a, 12 \\
3,12\end{array}$ \\
\hline $4 a$ & $75.95^{c}$ & & & \\
\hline $4 a-O H$ & & $6.53(\mathrm{OH}, \mathrm{s})^{\mathrm{c}}$ & & $10 a^{c}$ \\
\hline 5 & 193.19 & & & \\
\hline $5 a$ & 132.84 & & & \\
\hline 6 & 124.17 & $7.27(1 \mathrm{H}, \mathrm{d}, \mathrm{J}=7.8)$ & 7 & $5,8,9 a$ \\
\hline 7 & 137.00 & $7.64(1 \mathrm{H}, \mathrm{t}, \mathrm{J}=7.8)$ & 8,6 & $5 a, 9$ \\
\hline 8 & 119.33 & $7.57(1 \mathrm{H}, \mathrm{d}, \mathrm{J}=7.8)$ & 7 & $9 a, 6$ \\
\hline 9 & 162.21 & & & \\
\hline $9-\mathrm{OH}$ & & $11.61(\mathrm{OH}, \mathrm{s})$ & & $8,9,9 a$ \\
\hline $9 a$ & 115.78 & & & \\
\hline 10 & 198.97 & & & \\
\hline $10 a$ & $74.90^{c}$ & & & \\
\hline $10 \mathrm{a}-\mathrm{OH}$ & & $6.71(\mathrm{OH}, \mathrm{s})^{\mathrm{c}}$ & & $10^{c}$ \\
\hline 11 & 14.06 & $1.74(3 \mathrm{H}, \mathrm{d}, \mathrm{J}=7.2)$ & 1 & $1,10 a$ \\
\hline 12 & 40.34 & $2.62(1 \mathrm{H}, \mathrm{dd}, \mathrm{J}=15.6,9.7)$ & 3 & 4,13 \\
\hline & & $2.66(1 \mathrm{H}, \mathrm{dd}, \mathrm{J}=15.6,3.3)$ & 3 & 4,13 \\
\hline 13 & 171.49 & & & \\
\hline 14 & 51.98 & $3.72(3 \mathrm{H}, \mathrm{s})$ & & 13 \\
\hline
\end{tabular}

${ }^{a 13} \mathrm{C}-\mathrm{NMR}$ was measured at $150 \mathrm{MHz}$.

${ }^{b 1} \mathrm{H}-\mathrm{NMR}$ was measured at $600 \mathrm{MHz}$.

'NMR data for $4 \mathrm{a}, 10 \mathrm{a}, 4 \mathrm{a}-\mathrm{OH}$ and $10 \mathrm{a}-\mathrm{OH}$ were measured in DMSO- $d_{6}$

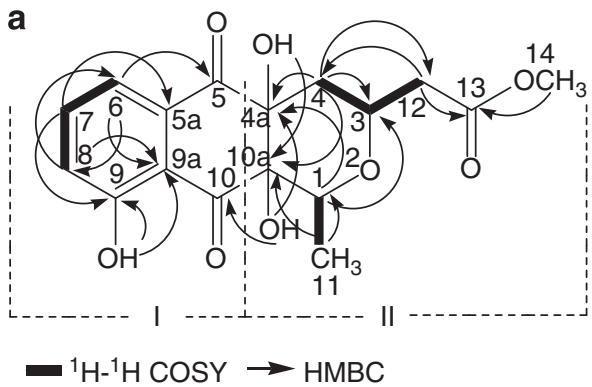

of $\delta 198.97$ (C-10) was assigned. It led to the unambiguous assignments of NMR data in the substructure I (Figure 2).

As the three-carbonyl carbons and one benzene ring in $\mathbf{1}$ accounted for seven of the nine degrees of unstauration required for the molecular formula, 1 should have another two rings. This was confirmed by tracing cross peaks in the ${ }^{1} \mathrm{H}-{ }^{1} \mathrm{H}$ COSY and HMBC from the two oxy-methine protons at $\delta 4.32(1 \mathrm{H}, \mathrm{q}, \mathrm{J}=7.2 \mathrm{~Hz}, 1-\mathrm{H}), \delta$ $4.59(1 \mathrm{H}, \mathrm{m}, 3-\mathrm{H})$ and the two methene protons at $\delta 1.95(1 \mathrm{H}, \mathrm{dd}$, $\mathrm{J}=2.4,12.6 \mathrm{~Hz}, 4-\mathrm{H}), \delta 2.28(1 \mathrm{H}, \mathrm{dd}, \mathrm{J}=15.0,12.6 \mathrm{~Hz}, 4-\mathrm{H})$ observed in ${ }^{1} \mathrm{H}-\mathrm{NMR}$. The cross peaks in ${ }^{1} \mathrm{H}-{ }^{1} \mathrm{H}$ COSY between the protons at $3-\mathrm{H}$ and $\delta 2.28(1 \mathrm{H}, \mathrm{dd}, \mathrm{J}=15.0,12.6 \mathrm{~Hz} 4-\mathrm{H})$, together with the cross peaks in HMBC between $1-\mathrm{H}$ and $\mathrm{C}-4 \mathrm{a}(\delta$ 75.95), $1-\mathrm{H}$ and $\mathrm{C}-3$ $(\delta 62.38), 4-\mathrm{H}$ and $\mathrm{C}-10 \mathrm{a}(\delta 74.90)$ established the structure of the sixmembered tetrahydropyrane ring. The methyl proton signals at $\delta 1.74$ $\left(3 \mathrm{H}, \mathrm{d}, \mathrm{J}=7.2 \mathrm{~Hz}, 11-\mathrm{CH}_{3}\right)$ observed in ${ }^{1} \mathrm{H}-\mathrm{NMR}$ were assigned by ${ }^{1} \mathrm{H}$ ${ }^{1} \mathrm{H}$ COSY, and long-range coupling between $11-\mathrm{H}$ and $\mathrm{C}-1$ (74.47), $\mathrm{C}-10 \mathrm{a}$ in $\mathrm{HMBC}$ further confirmed its substitute position in the ring. A methyl acetate side chain linked with the ring at C-3 was identified by the contiguous correlation from $12-\mathrm{H}$ to $3-\mathrm{H}$ in ${ }^{1} \mathrm{H}-{ }^{1} \mathrm{H}$ COSY and correlations from proton signals at $\delta 2.62(1 \mathrm{H}, \mathrm{dd}, \mathrm{J}=15.6,9.7 \mathrm{~Hz}$, $12-\mathrm{H}), \delta 2.66(1 \mathrm{H}, \mathrm{dd}, \mathrm{J}=15.6,3.3 \mathrm{~Hz}, 12-\mathrm{H})$ to $\mathrm{C}-4(\delta 32.93)$ and $\mathrm{C}-13$ $(\delta$ 171.49), $\delta 3.72(3 \mathrm{H}, \mathrm{s}, 14-\mathrm{H})$ to $\mathrm{C}-13$ in HMBC. The cross peaks observed in $\mathrm{HMBC}$ between hydroxyl proton signals at $\delta 6.53$ $(4 \mathrm{a}-\mathrm{OH})$ and $\mathrm{C}-10 \mathrm{a}, \delta 6.71(10 \mathrm{a}-\mathrm{OH})$ and $\mathrm{C}-4 \mathrm{a}, 10 \mathrm{a}-\mathrm{OH}$ and $\mathrm{C}-10$, as well as $11-\mathrm{H}$ and $\mathrm{C}-10 \mathrm{a}$, indicated that $4 \mathrm{a}-\mathrm{OH}$ and $10 \mathrm{a}-\mathrm{OH}$ were linked to the tetrahydropyrane ring at C-4a and C-10a, respectively. These results indicated the presence of substructure II in $\mathbf{1}$ (Figure 2).

To satisfy nine degrees of unstauration required for the molecular formula, 1 must have another ring, and the linkage between the two substructures (I and II) was established by HMBC. The long-range coupling between $10 \mathrm{a}-\mathrm{OH}$ and $\mathrm{C}-10$ was observed in HMBC. The data above revealed the linkage of two substructures through $10 \mathrm{a}-\mathrm{C}$ with $10-\mathrm{C}$ and $4 \mathrm{a}-\mathrm{C}$ with 5-C. Rotating frame overhauser effect spectroscopy (ROESY) spectrum of $\mathbf{1}$ further confirmed the result. In the ROESY experiment, the correlation peaks were not observed between $4-\mathrm{H}(\delta 1.95,2.28)$ and $10 \mathrm{a}-\mathrm{OH}$, the correlation peaks were observed between $4-\mathrm{H}(\delta 1.95)$ and $4 \mathrm{a}-\mathrm{OH}$. Thus, the planar structure of 1 was determined.

The relative stereochemistry of $\mathbf{1}$ was determined by the analysis of ROESY (in dimethyl-d6 sulfoxide (DMSO- $\left.d_{6}\right)$ ) spectra. In the ROESY experiment, the correlation peaks were observed between 1- $\mathrm{H}$ and 10a$\mathrm{OH}$, between $3-\mathrm{H}$ and $11-\mathrm{H}, 4 \mathrm{a}-\mathrm{OH}, 4-\mathrm{H}(\delta 1.95)$ and between $4 \mathrm{a}-\mathrm{OH}$ and $4-\mathrm{H}(\delta 1.95), 11-\mathrm{H}$. However, the correlation peaks were not observed between 10a-OH and 4- $\mathrm{H}(\delta$ 2.28) (Figure 2). On the basis of the above results, the chemical structure of $\mathbf{1}$ was determined as shown in Figure 1. It was a new member of nanaomycins group of antibiotics and was named 2754A.

b

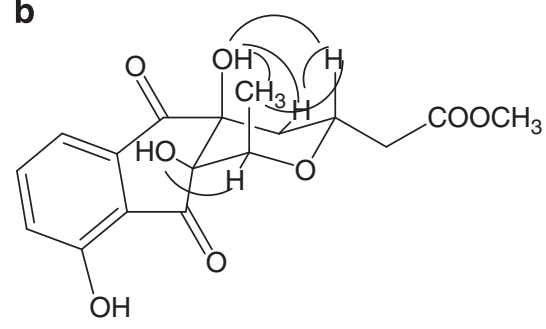

Figure 2 (a) Summary of ${ }^{1} \mathrm{H}-{ }^{1} \mathrm{H}$ COSY and selected HMBC correlations of 1. (b) ROESY spectrum of 1. 
1 belongs to benzoisochromane-quinone class of antibiotics and is most closely related to nanaomycin $\alpha \mathrm{B}$ produced by Streptomyres sp. OM-173, which possess a hydrogen rather than a hydroxyl substituent on the 4a-position of the tetrahydropyrane ring. ${ }^{7}$ It was reported that nanaomycin-type antibiotics showed inhibitory activities against Gram-positive bacterias and fungi. ${ }^{5,7-11}$ However, 1 has no inhibitory activity against Candida albicans, Piricularia oryzae, Staphylococcus aureus, Bacillus subtilis, Sarcina lutea and Escherichia coli at $100 \mu \mathrm{g} \mathrm{ml}^{-1}$ using the paper ( $6 \mathrm{~mm}$ i.d.) disc method and does not have any cytotoxicities on the HCT-8 (human coloncancer), Bel-7402 (human hepatocarcinoma) and BGC-823 (human gastric carcinoma) cell lines at $10 \mu \mathrm{moll}^{-1}$ by the MTT [3-(4,5-dimethylthiazol2-yl)-2,5-diphenyltetrazolium bromide] assays, ${ }^{12}$ but was detected for the VEGFR-2 antagonistic activity using an ELISA assay method. ${ }^{13}$ In addition, nanaomycin $\alpha \mathrm{A}$ and nanaomycin $\beta \mathrm{A}$ isolated from Streptomyces sp. 2754 also were detected for the VEGFR-2 antagonistic activity.

The experimental procedures were described as follows: A random co-polymer of glutamic acid and tyrosine (poly (Glu, Tyr) 4:1) (Sigma) was coated on to a 96-well immunoplate (Nunc) at $37^{\circ} \mathrm{C}$ overnight $(2 \mu \mathrm{g} /$ well $)$. After washing the plate with phosphate-buffered saline (PBS) $\left(0.024 \% \mathrm{KH}_{2} \mathrm{PO}_{4}, 0.144 \% \mathrm{Na}_{2} \mathrm{HPO}_{4}, 0.02 \% \mathrm{KCl}\right.$ and $0.8 \% \mathrm{NaCl}, \mathrm{pH} 7.4$ ) three times and blotting dry, the purified recombinant VEGFR-2-CD (the catalytic core in intracellular tyrosine kinase domain) protein was dissolved in TK buffer ( $50 \mathrm{~mm}$ Hepes, $\mathrm{pH}$ 7.4, $20 \mathrm{mM} \mathrm{MgCl}_{2}, 1.0 \mathrm{mM} \mathrm{MnCl}_{2}, 0.2 \mathrm{~mm} \mathrm{Na}_{3} \mathrm{VO}_{4}$ and $1 \mathrm{~mm}$ dithiothreitol). Then, $2 \mu \mathrm{l}$ of VEGFR-2-CD $(0.5 \mu \mathrm{g}), 50 \mu \mathrm{l}$ of ATP solution $(12.5 \mu \mathrm{M}$ ATP in TK buffer) and $50 \mu \mathrm{l}$ sample (dissolved in $10 \%$ DMSO) were added to each well. After being allowed to react at $37^{\circ} \mathrm{C}$ for $1 \mathrm{~h}$ and washing the plate five times with PBST (PBS with $0.1 \%$ Tween 20), $200 \mu \mathrm{l}$ of $5 \%(\mathrm{w} / \mathrm{v})$ bovine serum albumin in PBS was added to each well. After incubation for $1 \mathrm{~h}$ at $25^{\circ} \mathrm{C}$, the plate was washed five times with PBST and dried. Then, $100 \mu \mathrm{l}$ of mouse monoclonal antibody against phosphotyrosine (PY99) $(1: 1000(\mathrm{v} / \mathrm{v})$ dilution in PBS) was added to each well, and the plate was left at $25^{\circ} \mathrm{C}$ for $2 \mathrm{~h}$. The plate was washed again as described above before reaction with $100 \mu \mathrm{l}$ of secondary antibody, namely horseradish-peroxidaseconjugated horse anti-mouse polyclonal antibody IgG $(\mathrm{H}+\mathrm{L})$ (1:2000 (v/v) dilution; Zhongshan), at $25^{\circ} \mathrm{C}$ for $1 \mathrm{~h}$. After final washing as described above, 3, 3', 5, 5'-tetramethylbenzidine solution (You Yi Biotechnology Company, Beijing, China) and $\mathrm{H}_{2} \mathrm{O}_{2}$ each $50 \mu \mathrm{l}$ was added to each well, and the reaction was allowed to proceed at $25^{\circ} \mathrm{C}$ for $1 \mathrm{~h}$ (during which the solution should turn blue), before the reaction was stopped by the addition of $100 \mu \mathrm{l}$ of $1 \mathrm{M} \mathrm{HCl}$. The reaction was monitored by measuring the optical density at $\mathrm{A}_{450}$. DMSO (10\%) was used as the negative control, The inhibition rate was calculated using the following equation:

Inhibition rate $(\%)=\left[1-\left(\mathrm{A}_{450} / \mathrm{A}_{450}\right.\right.$, control $\left.)\right] \times 100 \%$.

The VEGFR-2 antagonistic activities of 2754A, nanaomycin $\alpha \mathrm{A}$ and nanaomycin $\beta \mathrm{A}$ are shown in Figure 3.

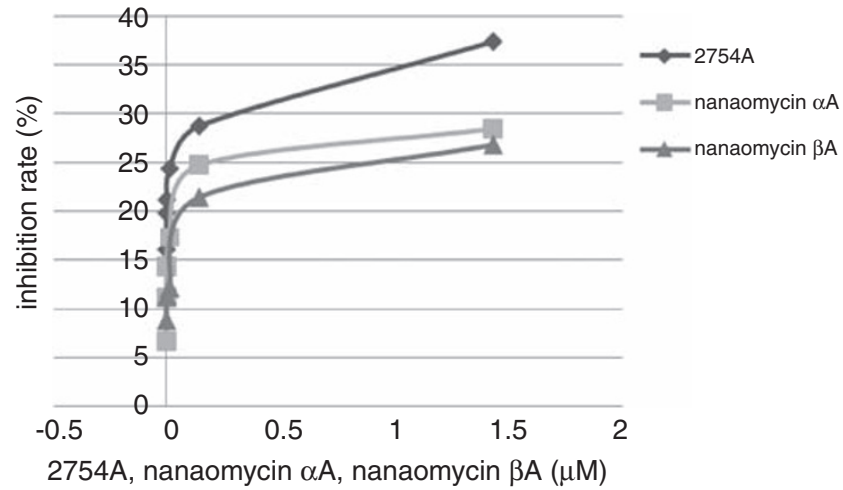

Figure 3 Inhibition of VEGFR-2/KDR by 2754A, nanaomycin $\alpha A$ and nanaomycin $\beta A$. The VEGFR-2 antagonistic activities were determined in an ELISA assay method, each assay point was determined in duplicate. 2754A, nanaomycin $\alpha \mathrm{A}$ and nanaomycin $\beta \mathrm{A}$ were isolated from Streptomyces $\mathrm{sp}$. 2754.

\section{ACKNOWLEDGEMENTS}

The study was supported by National S\&T Major Special Project on Major New Drug Innovation (Grant No. 2009ZX09301-003) funded by the Ministry of Science and Technology of the People's Republic of China.

1 Thomas, K. A. Vascular Endothelial Growth Factor, a Potent and Selective Angiogenic Agent. J. Biol. Chem. 271, 603-606 (1996).

2 Carmeliet, P. VEGF as a Key Mediator of Angiogenesis in Cancer. Oncology 69, 4-10 (2005).

3 Ferrara, N. \& Gerber, H. P. The Role of Vascular Endothelial Growth Factor in Angiogenesis. Acta. Haematol. 106, 148-156 (2001).

4 Ferrara, N. VEGF as a Therapeutic Target in Cancer. Oncology 69, 11-16 (2005).

5 Tanaka, H., Koyama, Y., Nagai, T., Marumo, H. \& Omura, S. Nanaomycins, New antibiotics produced by a strain of Streptomyces. J. Antibiot. 28, 868-875 (1975).

6 Tsukamoto, M. et al. New Cytotoxic Agents, BE-52440A and B, Produced by a Streptomycete. J. Antibiot. 53, 687-693 (2000).

7 Iwai, Y. et al. OM-173, New nanaomycin-type antibiotics produced by a strain of Streptomyces. Taxonomy, production, isolation and biological properties. J. Antibiot. 36, 1268-1274 (1983).

8 Omura, S. et al. Nanaomycins A and B, New Antibiotics Produced by a strain of Streptomyces. J. Antibiot.. 27, 363-365 (1974).

9 Tanaka, H., Marumo, H., Nagai, T., Okada, M. \& Taniguchi, K. Nanaomycins, new antibiotics produced by a strain of Streptomyces. III. A new component, Nanaomycin C, and biological activities of nanaomycin derivatives. J. Antibiot.. 28, 925-930 (1975).

10 Omura, S., Tanaka, H., Okada, Y. \& Marumo, H. Isolation and structure of nanaomycin D, an enantiomer of the antibiotic kalafungin. J. Chem. Soc., Chem. Commun 1976, 320-321 (1976).

11 Kasai, M. et al. Structure of Nanaomycin E, a new nanaomycin. J. Antibiot. 32, 442-445 (1979).

12 Mosmann, T. Rapid colorimetric assay for cellular growth and survival: application to proliferation and cytotoxicity assays. J. Immunol. Methods 65, 55-63 (1983).

13 Liu, C., Guo, L., Yao, C., Zhang, R. \& Li, Y. Expression and purification of human vascular endothelial growth factor receptor 2 tyrosine kinase in Streptomyces for inhibitor screening. Biotechnol. Appl. Biochem. 50, 113-119 (2008). 